\title{
Relation between apex cardiographic and internal indices of left ventricular relaxation in $\operatorname{man}^{1}$
}

\author{
JAN MANOLAS ${ }^{2}$ AND WILHELM RUTISHAUSER ${ }^{3}$
}

From the Department of Internal Medicine, Medical Policlinic, University of Zurich, Zurich, Switzerland

In 19 patients the left apex cardiogram was recorded by a transducer with infinite time constant; at the same time left ventricular (tip manometer) and aortic pressures were recorded during cardiac catheterisation. The relation between two relaxation time intervals in the apex cardiogram and haemodynamic as well as angiocardiographic indices of left ventricular performance were studied. These apex cardiographic time intervals were: (1) the time from the onset of the aortic component of the second heart sound $\left(S_{2}\right)$ in the phonocardiogram to the negative peak of the first derivative $(d A / d t)$ of the apex cardiogram, termed early apex cardiographic relaxation time, and (2) the time from $S_{2}$ to the point where $d A / d t$ after having reached its negative peak ascends to the zero line, termed total apex cardiographic relaxation time.

In 100 normal subjects early apex cardiographic relaxation time averaged $3 \pm 12$ ( \pm 1 SD) ms and total apex cardiographic relaxation time was $93 \pm 16 \mathrm{~ms}$. In 11 patients with non-obstructive cardiomyopathy and decreased left ventricular function early and total apex cardiographic relaxation times were significantly $(P<0.001)$ prolonged $(52 \pm 23 \mathrm{~ms}$ and $152 \pm 23 \mathrm{~ms}$, respectively), whereas in 8 patients without or with only minimal left ventricular pressure or volume overload they were within normal limits $(-1 \pm 8$ ms and $94 \pm 9 \mathrm{~ms}$, respectively).

The following significant correlations were observed between early apex cardiographic relaxation time and internally measured indices of left ventricular performance: maximal rate of pressure fall (min $d P / d t)$ in the left ventricle $(r=-0.87)$, velocity of lengthening of the contractile elements at minimum $d P / d t(r=-0.83)$, and ejection fraction $(r=-0.80)$; significant correlations with several other values of left ventricular function (end-diastolic pressure, maximal $d P / d t$, and peak measured velocity of shortening of the contractile elements) were also observed. In the total group of subjects total apex cardiographic relaxation time correlated significantly with early apex cardiographic relaxation time $(r=+0.67)$; further, in the catheterised patients total apex cardiographic relaxation time showed less close correlation with the internal indices.

The early and total relaxation time intervals in the left apex cardiogram are two important noninvasive methods for assessing left ventricular performance in man.

Evaluation of the left ventricular performance by noninvasive techniques is desirable, because conventional invasive methods are time consuming, expensive, and involve some risk for the patient. It has been shown that the apex cardiogram reflects left ventricular events accurately enough in a qualitative (Benchimol et al., 1961; Epstein and Coulshed, 1973; Manolas et al., 1975), and to some

${ }^{1}$ This work was supported partly by a grant from the Swiss National Science Foundation.

'Present address: Department of Clinical Therapeutics, University of Athens, School of Medicine, Athens, Greece.

'Present address: Centre de Cardiologie, Hopital Cantonal, Genève, Switzerland.

Received for publication 25 February 1977 extent also quantitative fashion (Reale, 1967; Sutton et al., 1970; Vetter et al., 1972; Manolas et al., 1974; Denef et al., 1975; Manolas et al., 1976; Manolas and Krayenbuehl, 1976). The use of amplitude parameters in the apex cardiogram has not been feasible because of their inherent dependence on thoracic shape and lack of generally accepted calibration methods. The significance of the time interval from the onset of the second heart sound to the protodiastolic nadir of the apex tracing for the identification of the opening snap in the phonocardiogram has been pointed out in the past by some authors (Legler et al., 1963; Oriol et al., 1965). Benchimol and Ellis (1967) first suggested 
that this time interval was identical with the isovolumic relaxation period and concluded that this interval might 'be a useful avenue to the study of the condition of left ventricular function in man'.

The present study was designed to assess the clinical value of relaxation time intervals measured from the apex cardiogram by simultaneous recording of its first derivative and the phonocardiogram by (1) defining the normal values of these intervals, (2) comparing patients with impaired left ventricular function with controls, (3) correlating the apex cardiographic relaxation intervals with internally measured indices of left ventricular performance, and (4) comparing these correlations with those of widely used isovolumic time measurements (Mason et al., 1965; Spodick and Kumar, 1968) with the same haemodynamic indices.

\section{Subjects and methods}

\section{SUBJECTS}

Apex cardiograms were recorded in 119 subjects, all of whom had sinus rhythm. In 100 healthy individuals apex tracings alone were recorded, whereas in the other 19 subjects apex cardiograms were recorded during left heart catheterisation. The catheterised patients were premedicated with $10 \mathrm{mg}$ chlordiazepoxide or $5 \mathrm{mg}$ diazepam given orally one hour before the procedure. Informed consent was obtained from each person.

\section{Group $1 a$}

This group consisted of the 100 healthy volunteers with no cardiovascular abnormality as detected on physical examination, $x$-ray film, or electrocardiogram, in whom apex tracings alone were recorded in order to establish the normal range of the apex cardiographic relaxation time intervals and to evaluate the possible influence of the resting heart rate on them.

\section{Group $1 b$}

This group consisted of 8 patients without left heart valvular disease and without, or with only slight, pressure or volume overloading of the left ventricle; 3 patients had a small persistent ductus and 1 had a small ventricular septal defect (all 4 patients with a left-to-right shunt of less than $15 \%$ of the pulmonary flow). One patient had slight valvular pulmonary stenosis (peak pressure gradient $18 \mathrm{mmHg}$ ), 1 had a mild form of a coarctation of the aorta (peak pressure gradient $9 \mathrm{mmHg}$ ), 1 had a stenosis of the innominate artery, and 1 a functional murmur with paroxysmal supraventricular tachycardias. Left ventricular performance was determined by measuring the isovolumic indices at rest and during hand- grip test (Krayenbuehl et al., 1972, 1973) and was found to be within normal limits as was the ejection fraction in cineangiocardiogram of the left ventricle.

\section{Group 2}

This group consisted of 11 patients with nonobstructive cardiomyopathy and decreased left heart function at rest, as determined by the measurement of the isovolumic contractile indices and of the internal relaxation indices as well as by the ejection fraction; in most cases these patients showed an abnormal or pathological response on handgrip test (Krayenbuehl et al., 1972, 1973). Four patients had, in addition, slight mitral regurgitation (less than 0.12 regurgitation fraction as measured by thermodilution method); 3 patients also had labile arterial hypertension, 1 had a small persistent ductus arteriosus, 1 had a ventricular septal defect (both with a left-to-right shunt of less than 15 per cent of the pulmonary flow), and 1 had slight aortic stenosis (mean systolic pressure gradient determined by planimetry $6 \mathrm{mmHg}$ ).

\section{METHODS}

Apex cardiograms were recorded with the subject in the left lateral decubitus position, usually at an angle of 20 to $40^{\circ}$; the pulse transducer was held by hand at the point of maximal impulse of the apex beat of the heart. In healthy persons of group 1a apex tracings were also recorded in different positions, both of the body as well as of the axis of of the transducer, and with variation of the pressure applied to the transducer in relation to the chest wall, in order to evaluate the possible effects of these factors on the relaxation time intervals of the apex cardiograms. The pulse transducer was constructed in our laboratory (Manolas et al., 1975) and consisted of a Marey capsule (diameter $2 \mathrm{~cm}$ ) with the interior surface of this capsule directly connected without air leakage (Kastor et al., 1970) to a Bio-Tec-transducer (BT 250-T), which had a flat response at frequencies from $15000 \mathrm{~Hz}$ down to 0 with an infinite time constant; the distance from the transducer to the opening of the capsule measured $0.7 \mathrm{~cm}$. Because of its design this system had no measurable time delay (Piemme, 1963; Kesteloot et al., 1969).

Left heart catheterisation was performed using the percutaneous transfemoral technique. Pressure curves were obtained from the left ventricle and the ascending aorta by Statham $S_{1}$ or Millar catheter tipanometers but in some cases $8 \mathrm{~F}$ pigtail catheters were used for the aortic tracings. The micro-manometers were introduced into the left ventricle by the retrograde or transseptal approach and into the ascending aorta by the retrograde route. 


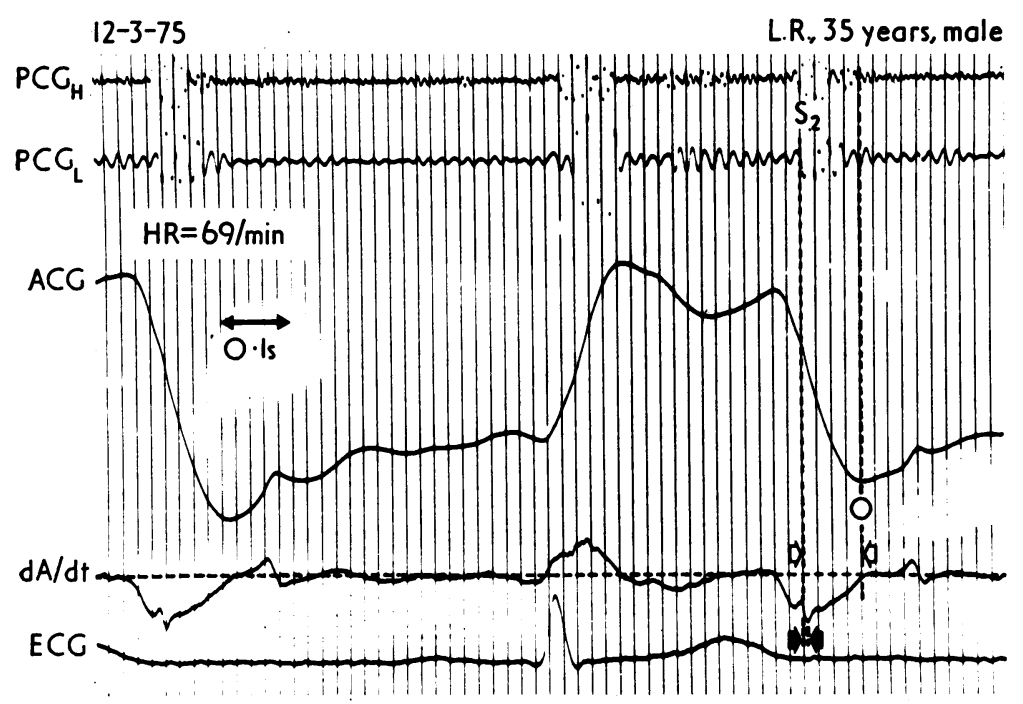

Fig. 1 Normal subject: simultaneous records of left apex cardiogram ( $A C G)$, its first derivative $(d A / d t)$, the external apical phonocardiogram ( $P C G_{\mathrm{H}}=$ high frequencies, $P C G_{\mathrm{L}}=$ low frequencies), and lead $I I$ of the electrocardiogram (ECG). $H R$, heart rate. $O$, protodiastolic nadir of the apex cardiogram. $S_{2}=$ onset of the aortic component of the second heart sound. Paper speed, $200 \mathrm{~mm} / \mathrm{s}$. The early apex cardiographic relaxation time $(E A R T)$ is indicated by closed arrows; whereas the total apex cardiographic relaxation time (TART) is indicated by open arrows. For further explanation see text.
Left ventriculography was carried out 40 to 70 minutes after recording the apex tracings. The patient was placed in the right anterior oblique position, and was told to hold his breath in midinspiration. Filming rate was 75 frames/s; 25 to $40 \mathrm{ml}$ Urografin 76 per cent was delivered by an electrocardiograph-triggered power injector into the left ventricle at a rate of 10 to $15 \mathrm{ml} / \mathrm{s}$. Further selective coronary arteriography was carried out using the Judkins technique. For the determination of ejection fraction the ventriculograms were viewed with a Tage-Arno projector; by playing back and forth, the largest (end-diastolic) and the

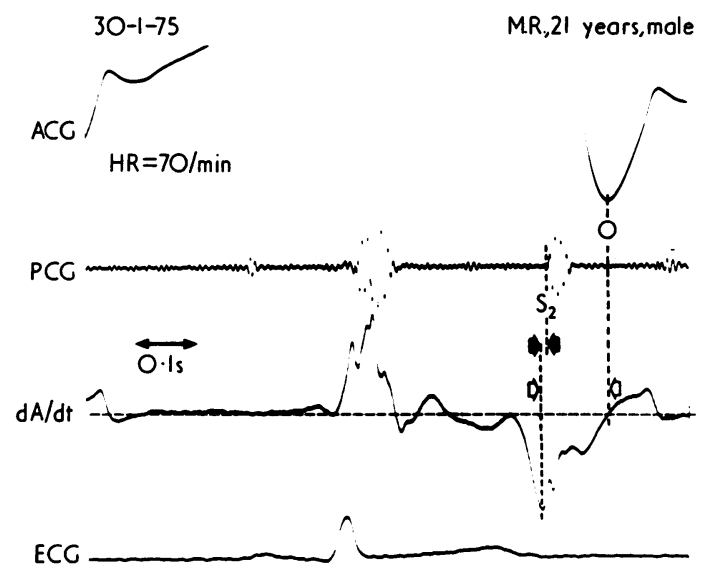

Fig. 2 Definition of the apex cardiographic relaxation time intervals by the use of the first derivative of the apex cardiogram (as indicated also in Fig. 1), recorded for illustrative purposes with high amplification. Abbreviations as given in legend of Fig. 1. For explanation see text. smallest (end-systolic) left ventricular silhouettes were identified and traced at the outermost endocardial border. Volumetric analysis was performed according to the area-length method (Dodge et al., 1966), whereby in the end-diastolic and end-systolic silhouettes the long ventricular axis was drawn from the mitral-aortic junction to the apex. Ejection fraction (EF) was calculated according to the formula:

$\mathrm{EF}=\frac{A_{S^{2}-L_{D}}}{A_{D^{2}}{ }^{2} L_{S}}$ where $A_{S}$ is end-systolic and $A_{D}$ is end-diastolic area, as determined by planimetry.

\section{ANALYSIS OF SIMULTANEOUS TRACINGS}

All tracings were recorded on an 8- or 16-channel Electronics for Medicine oscillograph (DR-16) at a paper speed $200 \mathrm{~mm} / \mathrm{s}$, with time lines at $20 \mathrm{~ms}$. In subjects of group la the apex cardiogram and its first derivative (dA/dt) were recorded simultaneously with the external apical phonocardiogram and lead II of the electrocardiogram (Fig. 1 and 2). In catheterised patients of groups $1 \mathrm{~b}$ and 2 the following tracings (Fig. 3) were also recorded: the left ventricular pressure, its first derivative $(\mathrm{dP} / \mathrm{dt})$, and the instantaneous quotient of $\mathrm{dP} / \mathrm{dt}$ to total left ventricular pressure $(\mathrm{dP} / \mathrm{dt}) / \mathrm{P}$, the last two being obtained by use of an analogue computer. The time constant of the computer for calculating $\mathrm{dP} / \mathrm{dt}$ and that of $\mathrm{dA} / \mathrm{dt}$ was $0.8 \mathrm{~ms}$, whereas that for calculating $(\mathrm{dP} / \mathrm{dt}) / \mathrm{P}$ was $1.1 \mathrm{~ms}$. In addition $(\mathrm{dP} / \mathrm{dt}) / \mathrm{P}$ was calculated manually. The peak measured velocity of shortening of the contractile elements $\left(V_{p m}\right)$ during the isovolumic phase of left ventri- 


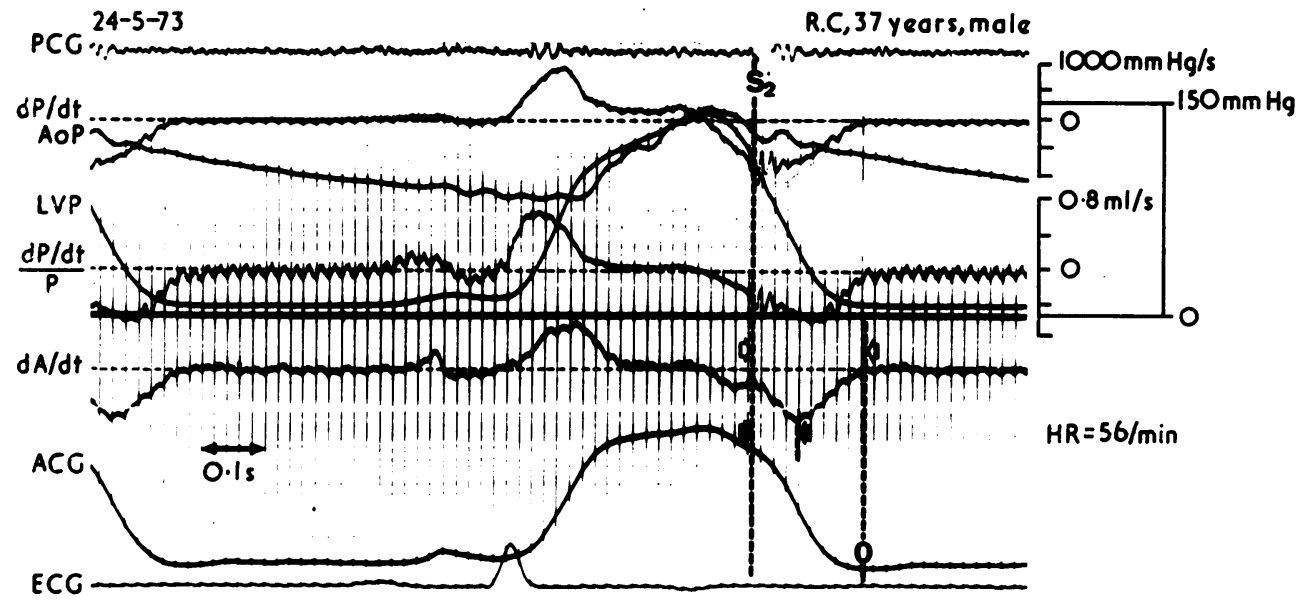

Fig. 3 Simultaneous recordings of the left apex cardiogram (ACG), left ventricular pressure (LVP), and their derivatives (dA/dt and $d P / d t$, respectively), instantaneous velocity of shortening of the contractile elements $[(d P / d t) / P]$, aortic pressure $(A o P)$, the external apical phonocardiogram (PCG), and the electrocardiogram (ECG) from a patient with nonobstructive cardiomyopathy and decreased left ventricular function. Paper speed, $200 \mathrm{~mm} / \mathrm{s}$. The apex cardiographic relaxation values (indicated by arrows as in Fig. 1 and 2) are much prolonged (EART, 69 ms and TART, $178 \mathrm{~ms}$ ).

cular systole was calculated according to the formula:

$\mathrm{V}_{\mathrm{pm}}$ in muscle lengths $/ \mathrm{s}=\max ([\mathrm{dP} / \mathrm{dt}] /[\mathrm{P} \cdot 28])$ where 28 is the coefficient of series elasticity; similarly the velocity of lengthening of the contractile elements at $\min \mathrm{dP} / \mathrm{dt}$ was determined ([min $\mathrm{dP} / \mathrm{dt}] /[\mathrm{P} \cdot 28])$, according to the value of $(\mathrm{dP} / \mathrm{dt}) /(\mathbf{P} \cdot 28)$ at the point of maximal pressure fall in the left ventricle, also in muscle lengths/s. The duration of the isovolumic phase of left ventricular systole was measured from the onset of the rise of the left ventricular pressure curve to the point of crossover of the left ventricle and aortic pressure curves. Measurements were also made of the time interval from the onset of left ventricular contraction to the peak of $\mathrm{dP} / \mathrm{dt}$ $(\mathrm{t}-\mathrm{dP} / \mathrm{dt})$.
Two relaxation time intervals were measured in the apex tracings: (1) the early apex cardiographic relaxation time, measured from the onset of the aortic component of the second heart sound $\left(S_{2}\right)$ in the phonocardiogram to the negative peak of $\mathrm{dA} / \mathrm{dt}$, and (2) the total apex cardiographic relaxation time measured from $S_{2}$ to the protodiastolic nadir of the apex tracing, the latter being defined more accurately by determining the point where $\mathrm{dA} / \mathrm{dt}$ after having reached its negative peak ascended and reached the zero line; this provides a more accurate temporal measurement of the protodiastolic nadir ( 0 point) of the apex tracing.

For each haemodynamic and apex cardiographic measurement 3 to 5 separate heart cycles were averaged.

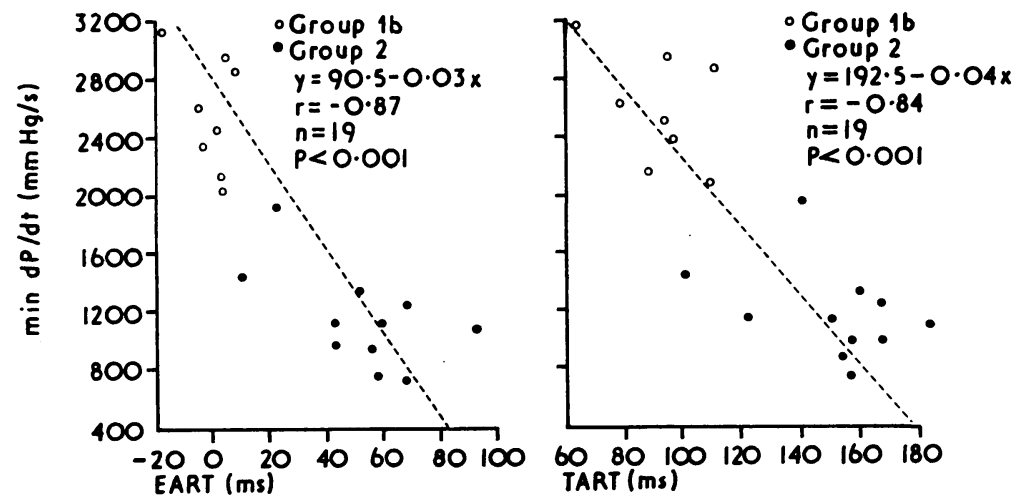

Fig. 4 Linear regression analyses between maximal value of the left ventricular pressure fall $(\min d P / d t)$ and $E A R T$ (left panel) and between min dP/dt and TART (right panel). 
Table 1 Summary of patient data

\begin{tabular}{|c|c|c|c|c|c|c|c|c|c|c|}
\hline Case No. & Age/Sex & Diagnosis & $\begin{array}{l}H R \\
\left(\min ^{-1}\right)\end{array}$ & $\begin{array}{l}E A R T \\
\text { (ms) }\end{array}$ & $\begin{array}{l}\text { TART } \\
\text { (ms) }\end{array}$ & $\begin{array}{l}I V C T \\
\text { (ms) }\end{array}$ & $\begin{array}{l}t-d P / d t \\
(m s)\end{array}$ & $\begin{array}{l}A o P \\
(m m H g)\end{array}$ & $\begin{array}{l}L V P_{\mathrm{ac}} \\
(m m H g)\end{array}$ & $\begin{array}{l}L V E D P \\
(m m H g)\end{array}$ \\
\hline $\begin{array}{c}\text { Group } 16 \\
1 \\
2 \\
3 \\
4 \\
5 \\
6 \\
7 \\
8\end{array}$ & $\begin{array}{ll}42 & F \\
19 & F \\
19 & F \\
28 & M \\
33 & F \\
21 & M \\
29 & M \\
23 & F\end{array}$ & $\begin{array}{l}\text { PS } \\
\text { PDA } \\
\text { PDA } \\
\text { Coarc. } \\
\text { STB } \\
\text { PDA } \\
\text { FM } \\
\text { VSD }\end{array}$ & $\begin{array}{l}76 \\
83 \\
71 \\
72 \\
73 \\
64 \\
65 \\
81\end{array}$ & $\begin{array}{r}+8 \\
+3 \\
+2 \\
-3 \\
+5 \\
+4 \\
-18 \\
-5\end{array}$ & $\begin{array}{r}113 \\
90 \\
95 \\
99 \\
96 \\
112 \\
65 \\
81\end{array}$ & $\begin{array}{l}80 \\
86 \\
51 \\
80 \\
73 \\
72 \\
80 \\
89\end{array}$ & $\begin{array}{l}54 \\
62 \\
49 \\
59 \\
64 \\
67 \\
67 \\
66\end{array}$ & $\begin{array}{c}131 / 82 \\
100 / 62 \\
97 / 64 \\
129 / 83 \\
141 / 88 \\
102 / 70 \\
182 / 109 \\
106 / 77\end{array}$ & $\begin{array}{r}115 \\
96 \\
90 \\
108 \\
133 \\
96 \\
142 \\
88\end{array}$ & $\begin{array}{c}6 /+3 \\
11 /- \\
12 /+2 \\
7 / 0 \\
11 / 0 \\
11 /+3 \\
12 /-3 \\
6 /-6\end{array}$ \\
\hline $\begin{array}{c}\text { Mean } \\
\pm \text { SD }\end{array}$ & $\begin{array}{r}28 \\
8\end{array}$ & & $\begin{array}{r}73 \\
7\end{array}$ & $\begin{array}{r}-1 \\
8\end{array}$ & $\begin{array}{r}94 \\
9\end{array}$ & $\begin{array}{l}76 \\
12\end{array}$ & $\begin{array}{r}61 \\
7\end{array}$ & $\begin{array}{r}124 / 79 \\
29 / 15\end{array}$ & $\begin{array}{r}109 \\
20\end{array}$ & $\begin{array}{r}10 / 0 \\
4 / 3\end{array}$ \\
\hline $\begin{array}{l}\text { Group } 2 \\
9 \\
10 \\
11 \\
12 \\
13 \\
14 \\
15 \\
16 \\
17 \\
18 \\
19\end{array}$ & $\begin{array}{ll}37 & M \\
54 & M \\
53 & M \\
62 & M \\
36 & M \\
34 & M \\
36 & M \\
41 & F \\
53 & M \\
32 & M \\
42 & M\end{array}$ & $\begin{array}{l}\text { CMP } \\
\text { CMP, AS } \\
\text { CMP, MR } \\
\text { CMP } \\
\text { CMP, VSD } \\
\text { CMP } \\
\text { CMP } \\
\text { CMP } \\
\text { CMP } \\
\text { CMP, PDA } \\
\text { CMP }\end{array}$ & $\begin{array}{l}56 \\
72 \\
66 \\
59 \\
82 \\
49 \\
67 \\
70 \\
63 \\
79 \\
49\end{array}$ & $\begin{array}{l}+67 \\
+60 \\
+68 \\
+52 \\
+10 \\
+56 \\
+43 \\
+43 \\
+58 \\
+22 \\
+93\end{array}$ & $\begin{array}{l}168 \\
154 \\
158 \\
161 \\
101 \\
157 \\
123 \\
167 \\
155 \\
144 \\
185\end{array}$ & $\begin{array}{r}112 \\
102 \\
126 \\
98 \\
74 \\
76 \\
87 \\
109 \\
115 \\
97 \\
76\end{array}$ & $\begin{array}{r}89 \\
89 \\
108 \\
78 \\
67 \\
67 \\
75 \\
88 \\
90 \\
77 \\
72\end{array}$ & $\begin{array}{c}143 / 80 \\
124 / 91 \\
91 / 58 \\
179 / 70 \\
113 / 74 \\
107 / 62 \\
165 / 99 \\
98 / 64 \\
104 / 68 \\
176 / 84 \\
153 / 102\end{array}$ & $\begin{array}{r}124 \\
145 \\
88 \\
150 \\
85 \\
94 \\
146 \\
79 \\
94 \\
121 \\
138\end{array}$ & $\begin{array}{l}12 /+8 \\
31 /+11 \\
8 /-1 \\
20 / 0 \\
18 /+10 \\
22 /+1 \\
50 /+23 \\
10 /+5 \\
10 /+13 \\
10 /-5 \\
32 /+6\end{array}$ \\
\hline $\begin{array}{l}\text { Mean } \\
+ \text { SD } \\
\mathbf{P}\end{array}$ & $\begin{array}{l}44 \\
10 \\
<0.001\end{array}$ & & $\begin{array}{l}67 \\
10 \\
\text { NS }\end{array}$ & $\begin{array}{l}+52 \\
23 \\
<0.001\end{array}$ & $\begin{array}{l}152 \\
23 \\
<0.001\end{array}$ & $\begin{array}{l}97 \\
18 \\
<0.01\end{array}$ & $\begin{array}{l}82 \\
12 \\
<0.001\end{array}$ & $\begin{array}{c}132 / 77 \\
32 / 15 \\
\text { NS/NS }\end{array}$ & $\begin{array}{r}115 \\
27 \\
N S\end{array}$ & $\begin{array}{l}20 /+6 \\
13 / 8 \\
\text { NS/NS }\end{array}$ \\
\hline
\end{tabular}

AoP, aortic pressure; AS, aortic stenosis; CMP, nonobstructive cardiomyopathy; EART, early apex cardiographic relaxation time; TART, total apex cardiographic relaxation time; EF, ejection fraction; HR, heart rate; IVCT, isovolumic contraction time; LVEDP, left ventriculare end-diastolic pressure (at rest/during handgrip; LVPac, left ventricular pressure at the level of the aortic closure; $M$, male; $F$, female; max dP/dt $\mathbb{D}$ maximal rate of rise of left ventricular pressure; $M R$, mitral regurgitation; min $\mathrm{dP} / \mathrm{dt}$, minimal rate of $\mathrm{dP} / \mathrm{dt} ;(\mathrm{min} \mathrm{dP} / \mathrm{dt}) /(\mathrm{P} \cdot 28)=\mathrm{velocity}$ of lengthen.ing of the contractile elements at $\mathrm{min} \mathrm{dP} / \mathrm{dt} ; \mathrm{P}$, probability; $\mathrm{PDA}$, persistent ductus arteriosus; $t-\mathrm{dP} / \mathrm{dt}$, time from the onset to peak $\mathrm{dP} / \mathrm{dt} ; \mathrm{V}$ pm peak measured velocity of shortening of the contractile elements; VSD, ventricular septal defect; ML, muscle length. Listed are mean values \pm SD 3 The $P$ values were obtained by the unpaired Student's $t$ test. NS, not significant $(P>0.05)$.

\section{Results}

Table 1 summarises the overall data obtained for haemodynamic, cineangiographic, and apex cardiographic measurements in the catheterised patients. The mean values of the following indices of left ventricular performance showed a significant difference at the level of $P<0.001$ in the two groups: the time from onset to the point of maximal rise of the left ventricular pressure ( $t-d P / d t)$, maximal rate of the left ventricular pressure rise (max $\mathrm{dP} / \mathrm{dt}$ ), maximal rate of pressure fall in the left venventricle $(\mathrm{min} \mathrm{dP} / \mathrm{dt})$, peak measured velocity of shortening of the contractile elements $\left(\mathrm{V}_{\mathrm{pm}}\right)$, and the velocity of lengthening of the contractile elements at $\mathrm{min} \mathrm{dP} / \mathrm{dt}\left([\mathrm{min} \mathrm{dP} / \mathrm{dt}] /\left[\mathrm{P} \cdot 28_{4}\right)\right.$, as well as the ejection fraction; further, the isovolumic contraction time (IVCT) at $\mathbf{P}<0.01$. Moreover, the age was significantly different $(P<0.001)$ in these two groups. In contrast, there was no significant difference between groups $1 \mathrm{~b}$ and 2 in the mean values of the heart rate, left ventricular end-diastolic pressure at rest and during handgrip test, systolic and diastolic aortic pressures, as well as the left ventricular pressure at the time of the aortic valve closure $/ \mathrm{LVP}_{\mathrm{ac}}$ ).

Table 2 Correlations between apex cardiographic relaxation parameters and internal indices of left ventricular performance

\begin{tabular}{|c|c|c|c|c|c|c|c|c|}
\hline & \multirow[t]{2}{*}{$I V C T$} & \multirow[t]{2}{*}{$t-d P / d t$} & \multirow[t]{2}{*}{$L V E D P$} & \multirow[t]{2}{*}{$\operatorname{Max} d P / d t$} & \multirow[t]{2}{*}{$\operatorname{Min} d P / d t$} & \multirow[t]{2}{*}{$V_{\mathrm{pm}}$} & $\operatorname{Min} d P / d t$ & $E F$ \\
\hline & & & & & & & \multicolumn{2}{|l|}{$P \cdot 28$} \\
\hline
\end{tabular}

$P$ values were for all correlations $<0.001$, except $\star P<0.01$ and $\star^{*} N S$. Abbreviations as in Table 1 . 


\begin{tabular}{|c|c|c|c|c|}
\hline $\begin{array}{l}\operatorname{Max} \\
d P / d t \\
(\operatorname{momHg} / \mathrm{s})\end{array}$ & $\begin{array}{l}\text { Min } \\
d P / d t \\
(m m H g / s)\end{array}$ & $\begin{array}{l}V_{\mathrm{pm}} \\
(\mathrm{ml} / \mathrm{s})\end{array}$ & $\frac{\operatorname{Min} d P / d t}{\begin{array}{l}P \cdot 28 \\
(\mathrm{ml} / \mathrm{s})\end{array}}$ & $E F$ \\
\hline $\begin{array}{l}2100 \\
1360 \\
1560 \\
1920 \\
1740 \\
1400 \\
2110 \\
1350 \\
1580\end{array}$ & $\begin{array}{c}2870 \\
2180 \\
2490 \\
2380 \\
2980 \\
2060 \\
3180 \\
2610 \\
1090\end{array}$ & $\begin{array}{l}1.99 \\
1.11 \\
1.16 \\
1.36 \\
1.18 \\
1.13 \\
1.24 \\
1.13 \\
0.80\end{array}$ & $\begin{array}{l}1.31 \\
1.96 \\
1.44 \\
1.92 \\
1.16 \\
0.91 \\
1.29 \\
1.80 \\
0.37\end{array}$ & $\begin{array}{l}0.83 \\
0.68 \\
0.73 \\
0.81 \\
0.64 \\
0.61 \\
0.67 \\
0.67 \\
0.50\end{array}$ \\
\hline $\begin{array}{r}1690 \\
320\end{array}$ & $\begin{array}{r}2590 \\
390\end{array}$ & $\begin{array}{l}1.29 \\
0.30\end{array}$ & $\begin{array}{l}1.47 \\
0.38\end{array}$ & $\begin{array}{r}0.71 \\
-0.08\end{array}$ \\
\hline $\begin{array}{r}960 \\
840 \\
530 \\
1120 \\
1040 \\
1080 \\
1060 \\
770 \\
720 \\
1340\end{array}$ & $\begin{array}{r}1220 \\
1120 \\
770 \\
1320 \\
1410 \\
990 \\
1110 \\
980 \\
780 \\
1980\end{array}$ & $\begin{array}{l}0.72 \\
0.47 \\
0.64 \\
0.70 \\
0.92 \\
0.74 \\
0.42 \\
0.66 \\
0.72 \\
0.93\end{array}$ & $\begin{array}{l}0.52 \\
0.40 \\
0.60 \\
0.37 \\
1.04 \\
0.48 \\
0.35 \\
0.42 \\
0.36 \\
0.71\end{array}$ & $\begin{array}{l}0.44 \\
0.33 \\
0.30 \\
0.37 \\
0.58 \\
0.40 \\
0.32 \\
0.40 \\
0.32 \\
0.52\end{array}$ \\
\hline $\begin{array}{l}1000 \\
290 \\
<0.001\end{array}$ & $\begin{array}{l}1160 \\
340 \\
<0.001\end{array}$ & $\begin{array}{l}0.69 \\
0.15 \\
<0.001\end{array}$ & $\begin{array}{l}0.51 \\
0.20 \\
<0.001\end{array}$ & $\begin{array}{l}0.41 \\
0.09 \\
<0.001\end{array}$ \\
\hline
\end{tabular}

Table 2 shows the correlation coefficients calculated by means of linear regression analyses for all catheterised patients using early or total apex cardiographic relaxation times as independent variables and indices derived from cardiac catheterisation data as dependent variables. Neither apex cardiographic relaxation time interval correlated significantly with $\mathrm{LVP}_{\mathrm{ac}}$ or systolic and diastolic aortic pressures.

Early apex cardiographic relaxation time is defined as the interval between $S_{2}$ of the phonocardiogram and the negative peak of the first derivative of the apex tracing. This interval could not be measured in 20 per cent of the normals (group 1a) because of the presence of multiple peaks in the derivative tracing; in addition, early apex cardiographic relaxation time had negative values in 27 per cent of these subjects, because the negative peak of $\mathrm{dA} / \mathrm{dt}$ preceded the onset of the aortic component of the second heart sound (Fig. 2). The value of the early apex cardiographic relaxation time was not, or was only slightly, influenced by differences in the position of the body as well as of the axis of the transducer and the extent of pressure to the transducer in relation to the thoracic wall. No significant linear correlation was present in the group 1a between early apex cardiographic relaxation time and resting heart rate $(r=-0 \cdot 16, P>0 \cdot 1)$ over a range from 49 to 118 beats/min as well as between early apex cardiographic relaxation time and the age $(r=+0.18, P>0.05)$ over a range from 17 to 50 years. Early apex cardiographic relaxation time in normal subjects averaged $3 \pm 12 \mathrm{~ms}$ ranging from -24 to $+20 \mathrm{~ms}$; it was significantly $(\mathrm{P}<0.001)$ prolonged in group $2(52 \pm 23 \mathrm{~ms})$, and within normal limits in group $1 \mathrm{~b}$ (Table 1 ).

The relations between early apex cardiographic relaxation time and internally measured indices in the catheterised patients are given in Table 2. The highest degree of correlation was found with min $\mathrm{dP} / \mathrm{dt}(\mathrm{r}=-0.87)$; and the correlation with ([min $\mathrm{dP} / \mathrm{dt}] /[\mathrm{P} \cdot 28]), \mathrm{EF}$ and $\mathrm{V}_{\mathrm{pm}}$ was very close to this. In contrast, the correlation with the isovolumic time indices (IVCT and $\mathrm{d}-\mathrm{dP} / \mathrm{dt}$ ) as well as with left ventricular end-diastolic pressure was close.

Total apex cardiographic relaxation time is defined as the interval from $S_{2}$ of the phonocardiogram to the protodiastolic nadir of the apex cardiogram, where the latter is given at the point where the first derivative reaches the zero line after having reached its negative peak; using this method of timing total apex cardiographic relaxation time could always be measured. Total apex cardiographic relaxation time was significantly $(P<0.001)$, but only very poorly, correlated with resting heart rate $(r=-0.32)$; less close, but also statistically significant $(P<0.01)$, was the correlation with age $(r=+0 \cdot 30)$. Total apex cardiographic relaxation time averaged $93 \pm 16 \mathrm{~ms}$ in normal subjects, the range being from 63 to $123 \mathrm{~ms}$; it was significantly prolonged $(P<0.001)$ in group $2(152 \pm 23 \mathrm{~ms})$. An identical significant inverse correlation was present, as shown in Table 1, between total apex cardiographic relaxation time and contractile relaxation indices $(\mathrm{min} \mathrm{dP} / \mathrm{dt}$ and $[\mathrm{min} \mathrm{dP} / \mathrm{dt}] /[\mathrm{P} \cdot 28])(\mathrm{r}=$ $-0.84)$; the correlations with other haemodynamic and ventriculographic values was less close. In contrast, there was no significant correlation with left ventricular end-diastolic pressure. Total apex cardiographic relaxation time was significantly $(P<0.001)$ correlated to early apex cardiographic relaxation time $(r=+0.67)$.

\section{INTERNAL INDICES OF LEFT}

\section{VENTRICULAR RELAXATION}

The interrelation between internally measured relaxation values and other contractile as well as ventriculographic indices was also examined in the present study. The maximal rate of left ventricular pressure fall, called min $\mathrm{dP} / \mathrm{dt}$, showed an excellent correlation with $\max \mathrm{dP} / \mathrm{dt}(\mathrm{r}=+0.93)$; less close 
were the correlations with ejection fraction ( $r=$ $+0.88)$ and with $V_{p m}(r=+0.83)$; all these correlations were significant at $P<0.001$. The velocity of lengthening of the contractile elements at min $\mathrm{dP} / \mathrm{dt}$, termed (min $\mathrm{dP} / \mathrm{dt}) /(\mathrm{P} \cdot 28)$, was significantly $(\mathrm{P}<0.001)$ correlated with ejection fraction $\mathrm{r}=$ $+0.88), V_{p m}(r=+0.73)$, and $\max \mathrm{dP} / \mathrm{dt}(r=$ $+0.63)$.

\section{INTERNAL TIME INDICES OF}

\section{LEFT VENTRICULAR PERFORMANCE}

In order to evaluate the relative importance of the noninvasively measured relaxation time indices derived from the apex tracing and the internally measured isovolumic time indices, linear regression analyses were performed using the latter as independent, and other indices of left ventricular performance as dependent variables.

The isovolumic contraction time correlated significantly $(\mathrm{P}<0.001)$ with $\max \mathrm{dP} / \mathrm{dt} \quad(\mathbf{r}=-0.69)$ and ejection fraction $(r=-0.67)$; in contrast, no significant correlation was observed with $V_{p m}$ $(r=-0 \cdot 25, P>0 \cdot 1)$. The time from the onset to peak $\mathrm{dP} / \mathrm{dt},(\mathrm{t}-\mathrm{dP} / \mathrm{dt})$, showed the highest degree of correlation with ejection fraction $(r=-0.84)$; it correlated less closely with $\max \mathrm{dP} / \mathrm{dt}(\mathrm{r}=-0.80)$, but both correlations were significant at $\mathrm{P}<0.001$. There was no significant correlation between $\mathrm{t}-\mathrm{dP} / \mathrm{dt}$ and $\mathrm{V}_{\mathrm{pm}}(\mathrm{r}=-0 \cdot 28, \mathrm{P}>0 \cdot 1)$.

\section{Discussion}

In recent years temporal measurements derived from the apex cardiogram have been examined for their value in assessing left ventricular function by analysis of simultaneous recordings of the left apex cardiogram and left ventricular pressure in human subjects. First Reale (1967) and recently Vetter et al. (1972) studied the value of the first derivative of the apex cardiogram. More recently the value of the systolic upstroke time of the apex tracing has been established (Manolas et al., 1976). The aim of this study was to compare relaxation time indices derived from the left apex tracing with other indices of cardiac performance derived from high fidelity left ventricular pressure curves and the cineangiocardiograms.

The experimental results of Cohn et al. (1972) in intact canine hearts showed the peak negative $\mathrm{dP} / \mathrm{dt}$ to be a more reproducible measure of the rate of relaxation', and they concluded that negative $\mathrm{dP} / \mathrm{dt}$ was related to the intrinsic contractility. Further, Hirzel et al. (1973) showed that min $\mathrm{dP} / \mathrm{dt}$ was the measurement first affected after coronary occlusion in dogs. Investigation of the relaxation velocity of the contractile elements, as indicated by the quotient $(\mathrm{dP} / \mathrm{dt}) / \mathrm{P}$, in ischaemic coronary disease was studied in this laboratory (Rutishauser et al., 1971, 1973) and it was concluded that 'relaxation was more altered than contraction'. These observations accord with the findings in our present study that both $\min \mathrm{dP} / \mathrm{dt}$ and $(\mathrm{min} \mathrm{dP} / \mathrm{dt}) /(\mathbf{P} \cdot 28)$ correlate significantly with isovolumic contractile indices ( $\max \mathrm{dP} / \mathrm{dt}$ and $\mathrm{V}_{\mathrm{pm}}$ ) as well as with the ejection fraction. Oriol et al. (1965) suggested 'a prediction of left atrial pressure from $\mathrm{S}_{2}-0$ interval'. However, the value of the apex cardiographic relaxation for assessing left ventricular function was first pointed out by Benchimol and Ellis (1967) suggesting that the interval from the onset of the second heart sound to the 0 point $\left(S_{2}-0\right)$ of the apex tracing was identical with the isovolumic relaxation time (IVRT) of the left ventricle; they found, from an excellent set of experiments, 'a decrease of IVRT during and after exercise' and that 'isoproterenol (isoprenaline) shortened IVRT', and concluded that there was 'no significant correlation between IVRT and age'. Recently Prewitt et al. (1975), comparing simultaneous recordings of echocardiogram and apex cardiogram found that 'the 0 point coincides neither with the initial nor with maximum opening of the mitral valve leaflets'; according to this finding the $\mathrm{S}_{2}-0$ interval is not identical with the isovolumic relaxation time. In the present study we termed the $\mathrm{S}_{2}-0$ interval 'total apex cardiographic relaxation time' where the 0 point of the apex tracing was defined more accurately by the use of the first derivative of the apex tracing (Fig. 1 and 2).

Our findings show that total apex cardiographic relaxation time was significantly prolonged in most patients with nonobstructive cardiomyopathy and decreased left ventricular performance (Table 1). Further, it was closely correlated with internally measured indices of relaxation and less closely but significantly with isovolumic contractile indices and the ejection fraction (Table 2). In contrast, there was only a weak correlation with the resting heart rate in normal subjects so that a rate correction is not necessary. No significant correlation was found between total apex cardiographic relaxation time and age in the normals; this contrasts with the findings of Harrison et al. (1964).

A new index of apex cardiographic relaxation is introduced in the present communication. The early apex cardiographic relaxation time was defined as the interval between the $S_{2}$ and the negative peak of $\mathrm{dA} / \mathrm{dt}$. Our findings show that the early apex cardiographic relaxation time can be measured in patients with a decreased rate of relaxation because of the presence of a sharp and single 
peaked negative wave in the first derivative of the apex cardiogram. The mean value of the early apex cardiographic relaxation time was significantly prolonged in the patients with non-obstructive cardiomyopathy and impaired left ventricular performance compared with the normal subjects. The most important finding in the present study consists in the close correlation between early apex cardiographic relaxation time and the invasively measured indices of the relaxation of the left ventricle; moreover, a close relation was present with the ejection fraction and with the isovolumic contractile indices $(\max \mathrm{dP} / \mathrm{dt}$ and $\mathrm{Vxw}$ ). In contrast, there was no significant correlation between early apex cardiographic relaxation time and age in the group of normal subjects, thus agreeing with the findings of Benchimol and Ellis (1967). Furthermore, early qapex cardiographic relaxation time wa not significantly correlated with the resting heart rate. From these findings it can be concluded that the early apex cardiographic relaxation intervals are independent of these factors. Benchimol and Ellis (1967) pointed out that the 'isovolumic relaxation time' was dependent on three factors: (1) the rate of fall of left ventricular pressure, (2) the height of aortic or left ventricular pressure at the time of aortic valve closure, and (3) the height of left atrial pressure at the time of mitral opening. According to our findings in the present study both early and total apex cardiographic relaxation times showed no significant correlation with the left ventricular pressure at the time of aortic closure, or with systolic and diastolic aortic pressure; further, there was no signicant difference in the mean values of these pressures between the two groups of the catheterised patients, which could account for the differences in the mean values of the apex cardiographic relaxation time intervals between group $1 \mathrm{~b}$ and 2 . Furthermore, the correlations between apex cardiographic relaxation time intervals and left ventricular end-diastolic pressure (Table 2) were poor. Thus, it would appear that these apex cardiographic intervals are influenced by changes of slope of the left ventricular pressure curve after the closure of the aortic valve.

Comparing the relative importance of early and total apex cardiographic relaxation times as indices of left ventricular performance, it should be noted (Table 2) that early apex cardiographic relaxation time showed closer correlations to internal relaxation and contractile indices as well as ejection fraction. In this context it must be emphasised that early apex cardiographic relaxation time showed no significant correlation with the resting heart rate, whereas total apex cardiographic relaxation time showed a poor though significant correlation. When one compares the apex cardiographic relaxation time intervals and the isovolumic contraction time in their relation to internal indices of left ventricular function, it is evident that the former correlate more closely to isovolumic contractile indices and ejection fraction than the latter, where the correlation between the isovolumic contraction time and $\mathrm{V}_{\mathrm{pm}}$ was not significant. Mason et al. (1965) suggested the time to peak $\mathrm{dP} / \mathrm{dt}$ as an excellent index of the contractile state of the left ventricle; according to our findings in this study this isovolumic time index of contraction showed a closer correlation with ejection fraction compared with the apex cardiographic relaxation intervals, but it was less closely correlated to $\max \mathrm{dP} / \mathrm{dt}$ and not significantly to $\mathrm{V}_{\mathrm{pm}}$. These data clearly show the superiority of early and total apex cardiographic relaxation times over other internally measured temporal indices of left ventricular function.

\section{Conclusions}

No single index of undisputed value for assessing left ventricular performance in man is available. Isovolumic contraction and relaxation indices derived from left ventricular pressure curves have been widely used. However, their use in repeated evaluation of patients with cardiac disease is limited since they require left heart catheterisation. This study has shown that two relaxation time values, derived from the left apex tracing, show good correlation with internal contractile indices and with the ejection fraction. The great value of these indices derived noninvasively is further enhanced because the measurement is inherently simple. However, the magnitude of the correlation coefficients does not permit one to estimate with sufficient confidence in an individual subject the corresponding invasive indices of relaxation or the ejection fraction on the basis of the noninvasive measurements discussed above. It should also be noted that this study establishes the usefulness of the apex cardiographic relaxation times for the assessment of interpatient differences of basal contractile state in subjects without or with only a slight volume or pressure overload. The validity of early and total apex cardiographic relaxation time intervals for assessing changes in the inotropic state of the left ventricle as well as in the presence of moderate or severe valvular disease requires further investigation.

\section{References}

Benchimol, A., Dimond, E. G., and Carson, J. C. (1961). The value of the apex cardiogram as reference tracing in phonocardiography. American Heart fournal, 61, 485-493. 
Benchimol, A., and Ellis, J. G. (1967). A study of the period of isovolumic relaxation in normal subjects and in patients with heart disease. American fournal of Cardiology, 19, 196-206.

Cohn, P. F., Liedtke, A. J., Serur, J., Sonnenblick, E. H., and Urschel, C. W. (1972). Maximal rate of pressure fall (peak negative $\mathrm{dP} / \mathrm{dt}$ ) during ventricular relaxation. Cardiovascular Research, 6, 263-267.

Denef, B., Popeye, R., De Geest, H., and Kesteloot, H. (1975). On the clinical value of calibrated displacement apexcardiography. Circulation, 51, 541-551.

Dodge, H. T., Sandler, H., Baxley, W. A., and Hawley, R. R. (1966). Usefulness and limitations of radiographic methods for determining left ventricular volume. American fournal of Cardiology, 18, 10-24.

Epstein, E. J., and Coulshed, N. (1973). Phonocardiogram and apex cardiogram in systolic click-late systolic murmur syndrome. British Heart fournal, 35, 260-275.

Harrison, T. R., Dixon, K., Russell, R. O., Jr., Bidwai, P. S., and Coleman, H. N. (1964). The relation of age to duration of contraction, ejection, and relaxation of the normal human heart. American Heart fournal, 67, 189-199.

Hirzel, H. O., Meier, W., Krayenbuehl, H. P., and Mehmel, H. (1973). Left ventricular dynamics during acute ischemia in the dog. In Coronary Heart Disease, 2nd International Symposium, Frankfurt, 1972, p. 156. Ed. by M. Kaltenbach, P. Lichtlen, and G. C. Friesinger., Thieme, Stuttgart.

Kastor, J. A., Aronow, S., Nagle, R. E., Garber, T., and Walker, H. (1970). Air leaks as a source of distortion in apexcardiography. Chest, 57, 163-171.

Kesteloot, H., Willems, J., and Van Vollenhoven, E. (1969). On the physical principles and methodology of mechanocardiography. Acta Cardiologica, 24, 147-160.

Krayenbuehl, H. P., Rutishuser, W., Schoenbeck, M., and Amende, I. (1972). Evaluation of left ventricular function from isovolumic pressure measurements during isometric exercise. American fournal of Cardiology, 29, 323-330.

Krayenbuehl, H. P., Rutishauser, W., Wirz, P., Amende, I., and Mehmel, H. (1973). High-fidelity left ventricular pressure measurements for the assessment of cardiac contractility in man. American fournal of Cardiology, 31, 415-427.

Legler, J. F., Benchimol, A., and Dimond, E. G. (1963). The apex cardiogram in the study of the 2-OS interval. British Heart fournal, 25, 246-250.

Manolas, J., and Krayenbuehl, H. P. (1976). Assessment of left ventricular function in aortic incompetence by the systolic upstroke time of the apexcardiogram. (Abstract.) Circulation, 53-54, Suppl. II, 60.

Manolas, J., Rutishauser, W., Wirz, P., and Arbenz, U. (1975). Time relation between apex cardiogram and left ventricular events using simultaneous high-fidelity tracings in man. British Heart fournal, 37, 1263-1267.
Manolas, J., Wirz, P., Krayenbuehl, H. P., and Rutishauser, W. (1974). Kontraktilitätskriterien am simultan mit dem linksventrikulären Druck registrierten, frequenz- und amplitudengetreuen Apexkardiogramm. Schweizerische medizinische Wochenschrift, 104, 1590-1592.

Manolas, J., Wirz, P., and Rutishauser, W. (1976). Relationship between duration of systolic upstroke of apexcardiogram and internal indexes of myocardial function in man. American Heart fournal, 91, 726-734.

Mason, D. T., Sonnenblick, E. H., Ross, J., Jr., Covell, J. W., and Braunwald, E. (1965). Time to peak $\mathrm{dP} / \mathrm{dt}$ : a useful measurement for evaluating the contractile state of the human heart (abstract). Circulation, 31-32, Suppl. II, 145. Oriol, A., Palmer, W. H., Nakhjaran, F., and McGregor, M. (1965). Prediction of left atrial pressure from the second sound-opening snap interval. American fournal of Cardio$\log y, 16,184-188$.

Piemme, T. E. (1963). Pressure measurement: electrical pressure transducers. Progress in Cardiovascular Diseases, 5, 574-594.

Prewitt, T., Gibson, D., Brown, D., and Sutton, G. (1975). The 'rapid filling wave' of the apex cardiogram. Its relation to echocardiographic and cineangiographic measurements of ventricular filling. British Heart fournal, 37, 1256-1262.

Reale, A. (1967). Evaluation of the contractile state of the human heart from the first derivative of the apexcardiogram. Circulation, 36, 933-941.

Rutishauser, W., Amende, I., and Krayenbuehl, H. P. (1973). Course of relaxation of the left ventricle during stress tests in coronary disease. In Das chronisch kranke Herz, p. 341. Ed. by H. Roskamm and H. Reindell. Schaffauer Verlag, Stuttgart and New York.

Rutishauser, W., Amende, I., and Schoenbeck, M. (1971). Relaxation velocity of contractile elements in ischemic coronary heart disease. (Abstract.) Circulation, 43-44, Suppl. II, 220.

Spodick, D. H., and Kumar, S. (1968). Isovolumetric contraction period of the left ventricle. Results in a normal series and comparison of methods of calculation by atraumatic techniques. American Heart fournal, 76, 498-503.

Sutton, G. C., Prewitt, T. A., and Craige, E. (1970). Relationship between quantitated precordial movement and left ventricular function. Circulation, 41, 179-190.

Vetter, W. R., Sullivan, R. W., and Hyatt, K. H. (1972). Assessment of quantitative apex cardiography. A noninvasive index of left ventricular function. American Fournal of Cardiology, 29, 667-671.

Requests for reprints to Dr. Jan Manolas, 5 Pan Str., Paleon Psychicon, Athens, Greece. 